\title{
Victor Assis Brasil: a importância do período na Berklee School of Music (1969-1974) em seu estilo composicional
}

\author{
Marco Túlio de Paula Pinto (UNIRI0, Rio de janeiro, RJ)
}

mtuliosax@gmail.com

Resumo: Discussão sobre o papel do ambiente musical de Boston, especialmente da Berklee School of Music entre 1969 e 1974, no desenvolvimento do estilo composicional e das habilidades como arranjador de Victor Assis Brasil (1945-1981) e seus reflexos na parcela de sua produção musical que apresenta a mistura de elementos de música clássica, jazz e música brasileira.

Palavras-chave: jazz; composição; saxofone; Assis Brasil; Third Stream.

\section{Victor Assis Brasil: the importance of the Berklee School of Music period (1969-1974) on his compositional style}

Abstract: Discussion about the influence of the musical environment of Boston, especially that of the Berklee School of Music, between 1969 and 1974, on the development of the compositional style and arranging skills of Brazilian saxophone player and composer Victor Assis Brasil. (1945-1981), and its reflexes in his musical production which mixes elements from classical music, jazz and Brazilian popular music.

keywords: jazz; composition; saxophone; Victor Assis Brasil; Third Stream.

\section{1 - Introdução}

Este ensaio é parte de uma pesquisa que tem por objetivo estudar as interseções entre elementos do jazz, da música clássica e música popular brasileira na produção musical do saxofonista e compositor Victor Assis Brasil, à semelhança do movimento Third Stream, concebido por Gunther Schuller, em meados dos anos 1950. A proposta original era centralizar o foco das atenções na sua composição Suite para saxofone soprano e cordas, obra composta em 1973 e que teve sua estreia brasileira em 2 de maio de 1976, na Sala Cecília Meireles, tendo o autor como solista, acompanhado da Orquestra Sinfônica Nacional, sob a regência de Marlos Nobre. Entretanto, até o presente momento não se tem ideia do paradeiro desta obra, que se pode considerar paradigmática da confluência de estilos e matrizes sonoras, seja na for- ma de sua partitura, seja na forma de gravação. Após a consulta aos acervos particulares dos familiares e de arquivos das orquestras da região metropolitana do Rio de Janeiro e outros, como a Escola de Música da UFRJ, Rádio MEC, Museu da Imagem e do Som e Biblioteca Nacional não foi possível encontrar o manuscrito original ou algum tipo de cópia. Com o mesmo intuito, foram feitos alguns contatos com as bibliotecas das instituições norte-americanas Berklee College of Music, New England Conservatory e Boston Conservatory, igualmente sem êxito. Assim, devido à possibilidade de os esforços desta pesquisa não darem conta da localização da obra, restou ampliar o escopo a outras obras do compositor que também reúnam as mesmas características de fertilização mútua entre estilos musicais diversos. 
Victor Assis Brasil criou diversas composições que, em maior ou menor grau, estão a meio caminho entre o jazz e a música clássica. Escreveu para diversas formações: duos, trios, quartetos, big band, e essas obras demonstram que o seu trabalho ultrapassou as fronteiras do jazz, estilo ao qual o músico é geralmente associado.

0 presente texto discute as consequências do período compreendido entre 1969 a 1974, durante o qual o músico viveu em Boston, nos Estados Unidos da América, no desenvolvimento de suas habilidades como compositor e arranjador. Não se pretende estabelecer um vínculo direto entre a produção musical de Victor Assis Brasil e os preceitos de SCHULLER (1989) e BLAKE (1981), embora possam ser encontradas em suas obras muitas características comuns com a chamada Third Stream. 0 artigo é baseado em depoimentos de músicos que conviveram com o saxofonista, informações de encartes dos discos lançados, notas de programa e entrevistas do próprio artista.

\section{2 - Fontes sobre Victor Assis Brasil}

Uma das grandes dificuldades da pesquisa envolvendo Victor Assis Brasil é a carência de fontes a seu respeito. Apesar do reconhecimento de sua importância na música instrumental brasileira, há uma precariedade de informações sobre seu trabalho. Em tempos mais recentes alguns textos acadêmicos, como MAURITY (2006) e BARRETO (2007), têm abordado aspectos de sua música, sobretudo envolvendo análises de suas improvisações. Porém, até pouco tempo havia apenas algumas entrevistas do músico em jornais e revistas e uns poucos textos na Internet que carecem de rigor científico. Por exemplo, em um artigo, José Domingos Rafaelli afirma: "Em 1976, foi convidado pelo regente Marlos Nobre a apresentar, em primeira audição no Brasil, sua composição Suite Para Sax Soprano e Cordas com a Orquestra Sinfônica Brasileira, na Sala Cecília Meireles, do Rio de Janeiro". A afirmação traz uma informação incorreta. Na realidade a orquestra que acompanhou Victor na ocasião foi a Orquestra Sinfônica Nacional, da qual Nobre era diretor musical, fato este que pode ser comprovado pelo programa do concerto (Ex.1), que se encontra no arquivo da tradicional sala de concertos. Aliás, nesse documento a obra é referida como Suíte para Sax, Piano e Cordas.

Além disso, a ambiguidade do uso do pronome possessivo pode ter levado BEZERRA (2001), baseando-se presumivelmente no artigo de Rafaelli, a cair na armadilha linguistica e assumir uma incorreta interpretação do texto, creditando assim a Nobre a autoria da Suite, em seu artigo para um site especializado em música instrumental. A Internet é uma poderosa ferramenta dos tempos modernos, possibilitando o livre acesso a uma enorme quantidade de informações. Entretanto, torna-se um campo perigosamente fértil para a disseminação de informações incorretas ou imprecisas. MAURITY (2006), seja por basear-se no texto de BEZERRA, seja por também fazer uma interpretação incorreta do artigo de Rafaelli, acaba cometendo o mesmo equívoco.

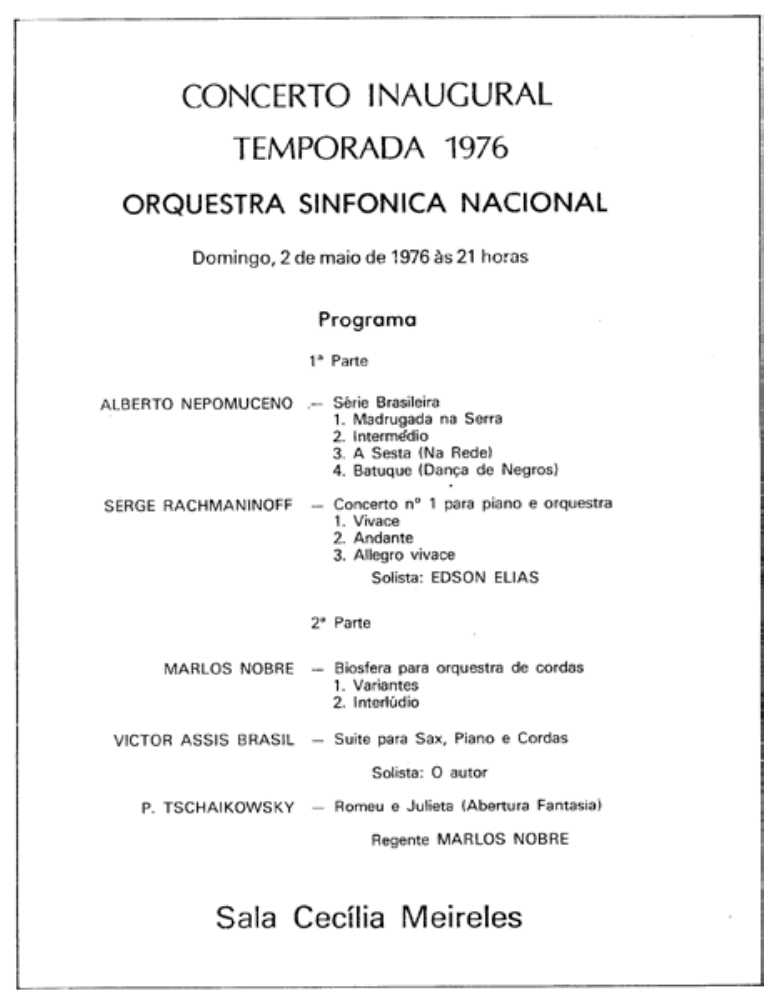

Ex.1 - Programa da estreia brasileira da
Suíte para Saxofone Soprano

A dissertação de MAURITY, intitulada A improvisação em Victor Assis Brasil propõe, através da transcrição e análise de solos, investigar a interação entre aspectos da música brasileira e do jazz na música do saxofonista. Para tal, 0 pesquisador faz um recorte sobre quatro temas dos dois últimos discos gravados por Victor. As canções escolhidas são: Blues for Mr. Saltzman e Penedo, de autoria de Victor Assis Brasil, Nada Será como antes, de Milton Nascimento e Fernando Brandt e 0 Cantador, de Dori Caymmi e Nelson Motta. A justificativa para esta delimitação do foco se baseia em serem amostras da fase mais madura do músico, na qual se encontram mais consolidadas as suas características de síntese entre o jazz e a música brasileira. 0 interesse de Maurity reside sobretudo na construção dos solos, as estratégias, técnicas e princípios utilizados no estilo do improvisador. 0 estudo funciona como um guia para músicos cuja prática musical faz uso recorrente da improvisação. Reconhece a importância de Victor no estabelecimento de uma linguagem brasileira na música instrumental, mesclando o idioma jazzístico com elementos nacionais. Neste ponto o pesquisador reflete sobre os dilemas, as críticas sofridas ao optar por uma prática musical considerada "americanizada" e o conflito entre suas múltiplas personalidades "de carioca, jazzman e músico universal" (MAURITY, 2006, p.10).

Já o trabalho de BARRETO (2007), intitulado Pro Zeca de Victor Assis Brasil: aspectos do hibridismo na música instrumental brasileira, analisa a manifestação simultânea de elementos de música brasileira e jazz, mais especificamen- 
te baião e bebop, na composição do saxofonista dedicada ao contrabaixista Zeca Assumpção. Sua fonte primária é o registro desta composição no LP Victor Assis Brasil, gravado ao vivo em 1974. 0 autor define esse processo como hibridação, ou hibridismo. No decorrer do texto descreve as características de cada estilo, demonstrando como estas se manifestam na composição em questão, concluindo que a hibridação, com a incorporação do idioma jazzístico a práticas vernaculares, tornou-se um traço marcante da música instrumental nos séculos XX e XXI.

Em sua tese Improvisação no Saxofone: A Prática da Improvisação Melódica na Música Instrumental do Rio de Janeiro a partir de meados do século XX, FIGUEIREDO (2005) discute a utilização da improvisação no desenvolvimento de uma linguagem corrente no meio musical carioca, com a incorporação de elementos da linguagem jazzística. Um dos procedimentos da pesquisa é a da entrevista com músicos proeminentes do cenário musical instrumental carioca. Diante da impossibilidade óbvia de entrevistar Victor Assis Brasil, falecido em 1981, prestaIhe um tributo, destinando algumas páginas de sua tese a traçar um perfil biográfico, aparentemente baseado nas parcas informações disponíveis citadas anteriormente. Por consequência, acaba cometendo o mesmo equívoco de MAURITY, ao divulgar informações incorretas sobre a autoria e estreia da Suite para saxofone soprano e cordas. De qualquer forma, o trabalho reconhece a importância do trabalho do saxofonista no estabelecimento da prática da improvisação no desenvolvimento da linguagem da música instrumental brasileira.

Como se pode perceber, os trabalhos mencionados discutem e analisam o lado mais conhecido da obra de Victor Assis Brasil: sua atuação como instrumentista, com destaque para suas habilidades como improvisador, além do fato de ser o músico, de certa maneira, um pioneiro e referência àqueles instrumentistas dedicados à prática da improvisação em sua atuação profissional. Esta pesquisa, mesmo reconhecendo a relevância desses aspectos em sua carreira, procura investigar um outro lado de sua produção: as obras nas quais o arranjador e compositor ultrapassa os limites estilisticos, unindo música clássica, jazz e música popular brasileira, oferecendo subsídios para a interpretação desse repertório.

\section{3 - 0 Movimento Third Stream e Victor Assis Brasil}

No início da década de 1960 o compositor Gunther Schuller cunhou a expressão Third Stream. Schuller iniciou sua carreira como trompista, tendo atuado tanto no jazz, notadamente no noneto comandado por Miles Davis e Gil Evans, quanto na música clássica, tendo tocado na Cincinatti Symphony e posteriormente na Metropolitan Opera Orchestra. Como educador, atuou em importantes instituições de ensino musical, como $M a-$ nhattan School of Music, Yale University, Tanglewood Music Center e New England Conservatory, do qual foi presidente entre 1967 e 1977. Lá criou o departamento de Third Stream, atualmente Contemporary Improvisation Department.

0 seu livre trânsito e sua admiração por ambas as esferas musicais contribuiram para sua concepção de uma música que reúne "a espontaneidade improvisacional e a vitalidade rítmica do jazz com os procedimentos e técnicas composicionais adquiridas na música ocidental durante 700 anos de desenvolvimento." (SCHULLER, 1986, p.115). Sua ideia inicial não era deflagrar um movimento ou criar um slogan, mas descrever um tipo de música que já existia, e carecia de denominação. 0 compositor vislumbrava um cenário onde a música de concerto do século XX e 0 jazz seriam as duas principais correntes estilisticas correndo paralelamente, e que em algum ponto começaria a haver uma troca mútua de elementos, dai nascendo a tal terceira corrente. De fato, este intercâmbio já pode ser notado em obras de Stravinsky, Milhaud, Copland, Gerswhin e outros, que tiveram o jazz como fonte inspiradora em muitas de suas obras. Por sua vez, os músicos de jazz demonstraram apreço e interesse pela música de concerto. Nomes como Coleman Hawkins (1904-1969), fundador de uma dinastia de grandes solistas no saxofone tenor, que se inspirava no violoncelo para obter sua sonoridade no instrumento, e que teria em sua coleção particular apenas discos de música clássica (SEGELL, 2006). Ou como o cornetista Bix Beiderbecke (1903-1931), um dos grandes músicos de jazz dos anos 20. Uma de suas composições que chegaram até o nosso tempo, In a Mist apresenta uma "abstração melancólica e um movimento harmônico rarefeito" que "apontam para ambições além do mundo da canção popular e do jazz" (GIOIA, 1997, p.90). Isto sem falar em Benny Goodman (1909-1986) e Woody Herman (1913-1987), que encomendaram e tocaram obras clássicas ${ }^{1}$ de importantes compositores do século $X X$. E não se pode ainda esquecer a monumental obra de Duke Ellington (1899-1974), que transcende qualquer classificação de estilos. De fato, essa miscigenação estilística sempre esteve presente na música sendo potencializada no século XX. Para GIOIA

\footnotetext{
...a idade moderna é marcada pela tendência de estilos distintos se amalgamarem e se fertilizarem mutuamente. Na música, pureza é um mito, embora resiliente. 0 historiador que espera poder vir a enfrentar as poderosas correntes de criatividade em tempos modernos deve aprender a lidar com estas complexas formas de arte em seus próprios termos ou de forma alguma Não há uma via expressa no mapa pós-moderno, apenas uma miriade de caminhos entrecruzados e divergentes ${ }^{2}$. GIOIA (1997, p.89)
}

0 próprio jazz, em sua essência, é o resultado do encontro da tradição europeia com as diversas práticas musicais trazidas da África. Aliás, este é um traço marcante comum à maior parte das músicas das Américas, marcadas pelo processo de aculturação decorrente do colonialismo e da escravatura. De qualquer modo, o certo é que desde muito cedo houve uma influência mútua entre a música clássica e o jazz.

0 termo Third Stream foi controverso e combatido por ambos os lados, sobretudo do meio jazzístico, sendo Schuller 
acusado de oportunismo e falta de "feeling" racial, o que o levou a se defender afirmando que não pretendia melhorar, substituir ou mesmo trazer o jazz para dentro da música de concerto. Algum tempo depois, o pianista Ran Blake ampliou o sentido do termo, que passou acolher as diversas manifestações vernaculares e étnicas (BLAKE, 1981).

Schuller concebia a Third Stream como um caminho lógico e inevitável para o curso da história da música. Entretanto, a fragmentação dos estilos jazzísticos, sobretudo o surgimento de duas tendências: o free jazz e a fusão do jazz com o rock, também conhecida como fusion ou jazz-rock, acabaram por enfraquecer o movimento. Ainda assim, podem ser percebidos traços característicos dessa fusão entre música clássica e jazz na obra de diversos artistas: The Modern Jazz Quartet, Stan Kenton, Charles Mingus, Toshiko Akiyoshi, Bob Mintzer, George Russel, e obviamente Blake e Schuller. Encounters, ambiciosa obra escrita em 2003 sintetiza o ideal de Schuller de uma música na qual o jazz e o clássico interagem. Sobre este trabalho escreveu o crítico musical Richard Dyer:

\footnotetext{
Encounters é uma improvável e delirantemente atraente obraprima orquestrada para 150 músicos, incluindo uma orquestra expandida, teclados, jazz ensemble e solistas de jazz. A obra inicia com um grito selvagem, e então um motivo suspirante; ambos aparecem o tempo todo. 0 grupo clássico e os instrumentos de jazz se alternam, mas logo começam a interagir em material musical compartilhado. 0 ágil jazz frequentemente tende a roubar o show dos grupos clássicos mais amarrados, mas o ouvido e a imaginação de Schuller para a cor orquestral não deixa isso acontecer; o terceiro movimento, com seus estrondos de não usuais instrumentos graves, é uma mágica musica noturna Bartokiana. 0 climax te faz levantar. (DYER, 2003)
}

Uma hipótese cogitada no início desta pesquisa é ter sido Victor Assis Brasil diretamente influenciado pelas ideias de Schuller, Blake, Russel e outros adeptos da third stream, pelo fato de o músico brasileiro ter residido em Boston justamente no período em que Schuller presidia o New England Conservatory, e este período coincidir também com suas obras de maior aproximação com a música clássica. Além da Suite para saxofone soprano, existem várias outras, geralmente curtas, camerísticas, que fogem do tradicional esquema do jazz tema-improvisos-tema. Uma busca preliminar no acervo de Paulo Assis Brasil, produtor musical e irmão do saxofonista, revela as seguintes obras (Ex.2):

Assim, era bastante plausivel que Victor tivesse sido afetado pela música que o grupo de compositores de Boston estava produzindo. Não havia muitos anos que 0

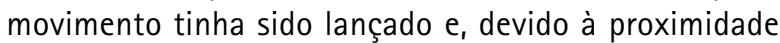
física, poderia possivelmente haver o intercâmbio entre as diversas escolas de música. Entretanto, depoimentos de amigos que presenciaram esse momento da vida de Victor Assis Brasil são contrários a essa hipótese. Um deles em especial: o trompetista Claudio Roditi, que vive hoje em dia nos Estados Unidos e é um dos mais respeitados músicos da atualidade. Claudio e Victor sempre tiveram uma intensa relação de amizade e afinidade musical. "Eram irmãos siameses na música" (AYRES, 2009). Estiveram juntos em vários momentos: nas jam sessions do Clube das Garrafas e do Clube de jazz e Bossa, nos festivais de jazz na Europa, no segundo disco gravado por Victor, nos tempos de Boston e da Berklee. 0 trompetista é taxativo ao afirmar que

\begin{abstract}
a influência da musica clássica na música do Victor veio do João Carlos Assis Brasil. 0 Victor sempre ouviu clássico, mais pela influência do João do que outra coisa. 0 movimento Third Stream que existia em Boston com o Gunther Schuller e o Ran Blake não influenciou o Victor, que eu saiba. ... Nós fomos colegas de apartamento na Áustria (Victor, João e eu) e o João teve muita influência no interesse que Victor teve pelo piano e pela música que João estudava todo o tempo. Entretanto o contrário também aconteceu, pois tempos depois João Carlos se interessou pelo jazz também. Eu acho que o movimento Third Stream não teve influência no Victor (RODITI, 2009).
\end{abstract}

Não há motivos para discordar de Roditi. Seu estreito convívio com Victor Assis Brasil, pessoal e musicalmente avaliza o seu depoimento. Deve-se ainda lembrar que o período no qual moraram na Áustria é anterior à viagem aos Estados Unidos, corroborando suas declarações. Mesmo que o compositor não tenha sofrido influência direta da chamada Third Stream, é fato que existe um número razoável de obras escritas pelo brasileiro que compartiIham das mesmas características descritas por Schuller, Blake et al., e é provável que o cenário musical de Boston, com a fartura de escolas e estudantes de música, tenha fornecido ambiente propício para suas experimentações no campo da composição e do arranjo.

\section{4 - A trajetória musical de Victor Assis Brasil}

\section{1 - 0 início da carreira e a identificação com o jazz.}

0 nome de Victor Assis Brasil está associado intimamente ao jazz. Suas próprias declarações davam conta de suas intenções de desenvolver um trabalho ligado a este estilo musical. Os depoimentos de músicos, críticos e aficionados sempre se referem ao músico como o "grande jazzista brasileiro", o " jazzman" e outros adjetivos do gênero. Mas é preciso lembrar alguns pontos. Em primeiro lugar, Victor não foi de maneira nenhuma um pioneiro, nem foi um representante de uma causa solitária. Havia um crescente interesse pelo jazz, que se no final dos anos 40 era mais restrito a espaços privados, como os fãs-clubes Sinatra-Farney e Dick Haynes-Lúcio Alves, na década seguinte iria se transferir para consagrados espaços noturnos de Copacabana, como o Copacabana Palace e as boates, Vogue's, Sacha's, Plaza, e posteriormente Little Club e Bottle's Bar. (SARAIVA, 2007, CASTRO, 1990). Victor começa a despontar no cenário musical carioca em 1964, sob o impacto da bossa-nova e sua incorporação do vocabulário harmônico jazzístico ao samba carioca, um samba novo, estilizado. Longe de passar pela discussão entre "saudosistas" e "modernistas" que acaloraram os debates sobre os rumos da música brasileira na época, o que interessa aqui é que havia na comunidade musical um grande número de instrumentistas que de fato faziam uso da linguagem do jazz. Nomes como o próprio Farney, Johnny Alf, Sérgio Mendes, Paulo Moura, J.T. Meirelles, Aurino Ferreira, Cipó, Luiz Eça, Baden Powell 


\begin{tabular}{|c|c|c|c|}
\hline$n^{\circ}$ & Título & instrumentação & data \\
\hline 1 & Asa Branca (arranjo) & big band & s.d. \\
\hline 2 & Marilia & big band & s.d. \\
\hline 3 & Dialogues ${ }^{4}$ & big band & s.d. \\
\hline 4 & Brazilian Sketches & big band & s.d. \\
\hline 5 & Faces & big band & s.d. \\
\hline 6 & Winter Songs & big band & s.d. \\
\hline 7 & Suite in Three & big band & s.d. \\
\hline 8 & Lines & Flugelhorn, 2 saxofones altos, trombone, baixo, piano & s.d. \\
\hline 9 & Minueto & piano & $04 / 03 / 75$ \\
\hline 10 & Ponteio \# 1 & piano & $20 / 08 / 75$ \\
\hline 11 & Reflexos & saxofone alto, vibrafone, baixo & $28 / 01 / 77$ \\
\hline 12 & Osmosis & saxofone alto, guitarra, cello & $23 / 03 / 77$ \\
\hline 13 & Estudo \# 1 & saxofone solo & \\
\hline 14 & Sem título & piano & $15 / 12 / 77$ \\
\hline 15 & Scattered Clouds & piano & $26 / 04 / 79$ \\
\hline 16 & Prelúdio & piano & $13 / 05 / 79$ \\
\hline 17 & Sem título & saxofone alto, piano & s.d. \\
\hline 18 & Sem título & saxofone alto, trompete, piano & s.d. \\
\hline 19 & Suite for a Lost Lady & trompete, saxofone soprano (alto), piano, baixo, bateria & s.d. \\
\hline 20 & One for Madam & piano & $28 / 03 / 73$ \\
\hline 21 & Mirage & metais e piano & s.d. \\
\hline 22 & Sem título & piano & s.d. \\
\hline 23 & Sem título & piano & set/73 \\
\hline 24 & Fugue & piano & set/73 \\
\hline 25 & Modinha & piano & $\mathrm{jan} / 74$ \\
\hline 26 & Penedo & piano, saxofone soprano & $\mathrm{dez} / 73$ \\
\hline 27 & Tema & saxofone tenor, trompete, trombone, piano, baixo, bateria & s.d. \\
\hline 28 & Prelude for trumpet piano and strings & trompete, piano, cordas & s.d. \\
\hline 29 & Visions & trompete, saxofone soprano, cordas & s.d. \\
\hline 30 & Prelude & quarteto de cordas & s.d. \\
\hline 31 & To Booker Little & piano, trompete & s.d. \\
\hline 32 & Mirage & Saxofone tenor, trompete, trombone, piano, baixo, bateria & s.d. \\
\hline 33 & Quarteto \#1 & quarteto de cordas & s.d. \\
\hline 34 & Modal & big band & s.d. \\
\hline 35 & Sem título & big band & s.d. \\
\hline 36 & Saxophone quartet \#1 & quarteto de saxofones (satb) & s.d. \\
\hline 37 & Prelude for alto sax and piano & saxofone alto e piano & s.d. \\
\hline
\end{tabular}

Ex.2 - Tabela com relação de obras de Victor Assis Brasil 
e tantos outros (CASTRO, 1990). A fusão entre a batida do samba, ainda que estilizada, e os sofisticados acordes do jazz, foram determinantes no estabelecimento da chamada 'música instrumental contemporânea brasileira', ou simplesmente 'música instrumental brasileira' (DAUELSBERG, 2001). A despeito da diversidade estilistica e da incorporação de elementos regionais, esta música instrumental que se faz até hoje se baseia em muito na prática jazzística, fundamentada na improvisação.

Mas, o que faz com que Victor Assis Brasil tenha atraído para si o rótulo de jazzista? Além obviamente de o jazz confessadamente ser uma parte proeminente do seu fazer musical, o saxofonista fez uma escolha em sua carreira artística que o diferencia da maioria dos instrumentistas, daqueles que o antecederam, de seus contemporâneos e dos que vieram depois. Ele decidiu se dedicar exclusivamente à sua música, renunciando a qualquer outro tipo de trabalho. Não tocou em bailes, acompanhou cantores ou participou de gravações de jingles, que sempre foram as atividades que sustentaram a carreira de muitos músicos, de ontem e de hoje. Victor pagou um preço por isso. Passou por enormes dificuldades financeiras para manter-se fiel a seus princípios. 0 testemunho de Roberto Sion corrobora essa afirmação:

Na minha opinião o Victor foi o único a ser somente um jazzman no Brasil. Dick Farney era pioneiro no jazz, Robledo, os saxofonistas da antiga, Abdon Lara, Cipó, Aurino, Juarez Araújo, Zé Bodega, todos esses adoravam jazz, como era a nossa escola, mas ninguém se dedicou a viver exclusivamente de jazz. Esse foi um dos méritos dele, e a coragem. E custou caro, estava sempre duro (SION, 2009).

Vindo de uma família carioca de classe média, Victor Assis Brasil é irmão gêmeo do pianista João Carlos Assis Brasil, que além de uma destacada carreira na música clássica, fez incursões pela música popular e pelo jazz. Sua avó paterna foi maestrina e diretora de conservatório. 0 primeiro instrumento musical foi a gaita, que começou a tocar aos 10 anos de idade. Mais tarde ganharia de uma tia o instrumento que se tornou seu maior meio de expressão, o saxofone ${ }^{5}$. Embora tenha tido algumas aulas com Paulo Moura, Victor demonstrou desde cedo um senso intuitivo muito forte e uma tendência a descobrir por si os caminhos musicais. Seu aprendizado se deu em muito através do processo de escuta e transcrição de solos de grandes músicos de jazz. Segundo João Carlos Assis Brasil seus favoritos eram Cannonball Adderley, Phil Woods e John Coltrane.

Em 1963 conheceu o trompetista Claudio Roditi, que viria a ser um grande amigo e parceiro musical. Nessa época, no colégio Andrews, tocavam em grupos separados: Victor com os irmãos Sauer e Claudio com Antonio Adolfo. Victor começou então a participar das jam sessions do Little Club, no lendário Beco das Garrafas, o que serviu para apresentar o jovem músico à comunidade musical. Em 1965 participou da estreia do Clube de Jazz e Bos$s a$, fundado por alguns jazzófilos, entre eles Jorge Guinle, Luiz Orlando Carneiro, José Domingos Rafaelli, Silvio Tulio Cardoso, Estevão Herman e outros, estando presente em muitas de suas reuniões subsequentes. Através des- te contato, foi convidado pelo clube e pelo Itamaraty a participar do Internationaler Wettbewerb für Modernen Jazz Wien 1966, organizado pelo pianista e compositor austriaco Friederich Gulda, cuja carreira se dividiu entre a música de concerto e o jazz. Sobre a participação de Victor neste festival as informações são controversas. Se Borelli e Rafaelli ${ }^{6}$ afirmam que o brasileiro terminou a competição em terceiro lugar na categoria saxofone, Celerier, em seu texto para a contracapa do segundo disco de Victor Assis Brasil, de 1968, afirma ter sido o segundo lugar a sua colocação. Assim também declara Alfredo Gomes (depoimento pessoal), baterista que tocou com Victor na década de 1960. 0 depoimento de Celerier está mais próximo no tempo da realização do festival, portanto seu conteúdo está menos sujeito à traição da memória. Todavia, mais importante que se estabelecer a real colocação de Victor Assis Brasil naquele evento, é lembrar que o vencedor da categoria saxofone na ocasião foi Eddie Daniels, um dos mais consagrados músicos da atualidade, músico referência na moderna clarineta do jazz, o que dá ideia do nível da competição. Na Europa, Victor participaria ainda do Festival de Berlim, tendo obtido o $1^{\circ}$ lugar na categoria saxofone. Ganhou ainda uma bolsa de estudos na cidade de Gratz e permaneceu em Viena juntamente com o irmão João Carlos e o amigo Claudio Roditi, que também embarcara para a aventura dos festivais.

Naquele mesmo ano de 1966, Victor Assis Brasil gravou seu primeiro disco, Desenhos, ao lado do pianista Tenório Jr., do contrabaixista Edison Lôbo e do baterista Chico Batera. 0 repertório inclui Naquela Base (Donato), Primavera (Carlos Lyra - Vinícius de Moraes), Simplesmente (Edson Lôbo), Feitiço da Vila (Noel Rosa - Vadico), Amor de Nada (Marcos e Paulo Sérgio Valle), Minha Saudade (João Donato - João Gilberto), além de quatro composições de Victor: Devaneio, Dueto, Eugenie e Desenhos. É um disco naturalmente influenciado pela bossa-nova e pelo samba jazz, caracterizado pela mistura entre os ritmos de samba-canção e samba a harmonias de jazz e blues, notadamente na composição de Lôbo.

Três faixas merecem destaque. A bela valsa Eugenie tem um lirismo e um sofisticado encadeamento harmônico que lembram o trabalho do pianista Bill Evans. Victor viria a ter uma especial atração pelo compasso $3 / 4$ como fica comprovado pelas diversas "waltzes" que ele escreveu no transcorrer de sua carreira.

A peça Dueto - que na realidade deveria se chamar trio, já que apenas o piano não toma parte - parece influenciada pelo antológico A Love Supreme, de John Coltrane. É uma obra intrigante que traz um longo diálogo entre saxofone e contrabaixo, pontuado por efeitos na bateria. Há uma alternância de seções que tem um caráter recitativo com outras mais ritmicas, com um clima latino acentuado. A obra apresenta ainda uma estrutura modal, sendo as ideias construidas sobre uma única escala, causando a sensação de uma nota pedal que se prolonga por toda a sua extensão, embora nem sempre esteja lá. 
Desenhos, a composição que dá nome ao disco, é um exemplo de que embora o jazz tenha um lugar de destaque na produção de Victor Brasil, está longe de ser uma referência única. Esta obra apresenta um ostinato do contrabaixo ao qual se aderem uma linha de saxofone, intervenções cordais do piano e efeitos da bateria. Há a um pequeno improviso do saxofone, mas não há a presença de uma "levada". 0 resultado é mais próximo de Satie que de Charlie Parker ou Cannonball Adderley. Um prenúncio de caminhos que levariam sua música para além dos domínios do jazz.

De volta da Europa, Victor continuou a participar das várias jam sessions na casa de amigos em Copacabana e Botafogo. Essas reuniões eram muito frequentes e eram importantes pela troca de informações e experiências entre músicos. Além de seu quinteto, que nessa época era formado pelo trompete de Roditi, o piano de Aloísio Aguiar, o contrabaixo de Sergio Barroso e a bateria de Claudio Caribe, Victor montou um outro grupo, um sexteto, no qual era ladeado pelo amigo inseparável Roditi, o pianista Haroldo Mauro Jr., o contrabaixista Ricardo Santos, o saxofonista Ion Muniz, também tocando alto, e o baterista Alfredo Gomes. 0 baterista fez sua estreia como músico profissional justamente com esse grupo, com o qual participou de diversos shows no Rio de Janeiro, com destaque para o espetáculo Ad Libitum, apresentado na Sala Cecília Meireles em 1968, que além do sexteto contou com a participação do Quinteto VillaLobos e de um septeto de dança coreografado por Sandra Dieken. (GOMES, 2008)

Seu segundo disco também foi gravado neste periodo, com a participação do quinteto ${ }^{9}$ acrescido de convidados, com destaque para o trombonista Edson Maciel e o guitarrista Helinho (Helio Delmiro). Este é um trabalho direcionado totalmente ao jazz. Ao contrário de Desenhos, marcado pelo clima de samba jazz, apresenta sobretudo tradicionais números de compositores norteamericanos. Round about midnight (Thelonious Monk) é apresentada sublimemente em trio de guitarra, saxofone e piano. What's this thing called Love (Cole Porter) traz um arranjo para big band de George André, com destaque para uma sensacional seção de saxofones: Victor Assis Brasil e Paulo Moura nos altos, Juarez Araújo e Oberdan Magalhães nos tenores. Há Mercy, Mercy, Mercy (Joe Zawinul), um grande sucesso de Cannonball Adderley. "E aquele cara chamado Robertinho que tá lá no disco sou eu tocando tenor. Só uma voz no Mercy, Mercy" (SION, 2009). 0 LP inclui ainda Search for peace (McCoy Tyner) e Summertime (G. Gershwin - Du Bose Heyward). Mesmo Stolen Stuff, composta por Victor, e Plexus, por Aloísio Aguiar, são obras escritas totalmente dentro do idioma jazzístico, afastadas de qualquer matriz brasileira, o que não revela intenção alguma de criar uma linguagem própria, mas uma tentativa de se estabelecer nos cânones estilísticos do jazz. Este é o momento em sua carreira onde o saxofonista abraça mais aberta e explicitamente este gênero musical.

\section{2 - A atividade musical de Victor Assis Brasil na Berklee}

Nos anos 1960 o aprendizado da música popular era feito de maneira totalmente informal. Não havia ainda escolas especializadas como o CLAM - Centro livre de aprendizagem musical, criado e dirigido pelos integrantes do Zimbo Trio, em São Paulo, em 1973, ou o CIGAM - Curso lan Guest de Aperfeiçoamento Musical, criado pelo compositor e arranjador húngaro no Rio de Janeiro, em 1987. Desta forma, aprendia-se música através do corpo a corpo, da troca de informações entre os colegas, e também da escuta e das transcrições de solos de artistas consagrados. Esta é uma prática ainda utilizada, sendo de grande valia para a assimilação de estilos. Mas mesmo isso era mais difícil naqueles dias, já que havia uma menor variedade de títulos disponíveis. Roberto Sion relata essa dificuldade.

Naquela época a gente não tinha uma discografia brasileira de jazz - Você ia 3, 4 anos nas lojas e estavam sempre os mesmos discos: Modern Jazz Quartet, tinha um do Chet Baker, um disco do Dave Brubeck, talvez o Time Out já tivesse saído. Essa enxurrada de informação que a gente tem hoje, de Cds era uma coisa inominável (SION, 2009).

Além disso, não havia os recursos eletrônicos que auxiliam no trabalho de transcrição, como programas que permitem diminuir a velocidade da gravação sem alterar a altura das notas, para a melhor compreensão de tempos e frases muito rápidos, ou isolar com precisão o trecho a ser transcrito. Todo o trabalho era feito com a imprecisão aleatória da agulha dos toca-discos. Através desse laborioso procedimento se deu a formação de várias gerações de instrumentistas.

A Berklee College of Music ${ }^{10}$, em Boston, Estados Unidos, foi a primeira instituição americana dedicada ao ensino do jazz. Com o decorrer do tempo, seu campo de atuação passou a abranger o rock e a música pop. A lista de ex-alunos inclui celebridades do jazz como Quincy Jones, Toshiko Akiyoshi, Joe Lovano, Gary Burton, Al di Meola, Joe Zawinul, Makoto Ozone, Branford Marsalis entre outros. A universidade atende a 4.000 alunos e tem 300 ensembles de alunos, 300 salas para ensaios e 13 estúdios completos de gravação como alguns de seus inúmeros recursos $^{11}$. Os números são atuais, mas mesmo em 1969, quando a estrutura da escola era bem menor, o abismo entre seus recursos e o aparato disponivel no Brasil, ou seja, nenhum, era gritante.

Nelson Ayres, Victor Assis Brasil e Claudio Roditi estão entre os primeiros brasileiros a estudarem em Berklee. Depois vieram muitos outros: Roberto Sion, Zeca Assumpção, Célia Vaz, Alfredo Cardin, Claudio Caribé, Helio Delmiro e uma legião de músicos. A escola viria a se tornar a Meca dos brasileiros interessados a aprender o idioma jazzístico.

0 que se sabe da vida acadêmica de Victor Assis Brasil em Berklee, considerando-se que ele teve uma, é dado pelo depoimento dos amigos que lá estiveram no mesmo período. Caberia uma pesquisa de campo para levantar 
registros acadêmicos e outros documentos relatando sua atuação naquela instituição.

0 compositor Nelson Ayres costuma dizer ter sido o primeiro brasileiro a estudar em Berklee, embora Victor Assis Brasil tenha lá chegado dois dias antes que ele. Acontece que, segundo Ayres (2009), o saxofonista nunca conseguia acordar para as aulas matutinas. De fato, vários depoimentos dão conta de sua falta de assiduidade na escola. Vários fatores podem ter levado a isso: uma desestruturação de comportamento, uma tendência à boemia. Entretanto, vários depoimentos confluem para uma desilusão, de certo modo, uma frustração da expectativa pelo que iria encontrar nos Estados Unidos. 0 irmão, João Carlos Assis Brasil, costuma dizer que quando Victor chegou a Berklee para estudar saxofone, os professores perguntaram se ele estaria ali para aprender ou para ensinar o instrumento, devido ao seu avançado nível técnico. Este relato poderia muito bem soar como uma declaração de admiração de um irmão devotado, assumindo até um caráter ufanista. Entretanto, diversos depoimentos ratificam essa afirmação. A compositora Célia Vaz diz que "ele estava também 10.000 pontos na frente daquilo tudo. Ele daria aula para os professores." (VAZ, 2008). Ayres afirma:

\begin{abstract}
Acho que ele, como músico, naquela época já era muito superior à maioria dos professores e não se interessava pela coisa acadêmica. De qualquer maneira a Berklee é uma faculdade e você tem aquelas "História do Jazz", "Harmonia Tradicional" e coisas que talvez ele não tivesse "saco" para aprender. Ele gostava de tocar. A tarde e à noite ele estava lá na escola tocando com o pessoal, de brincadeira, jam sessions. Mas do que eu saiba ele nunca teve exame, ou teve nota. (AYRES, 2009)
\end{abstract}

0 músico americano Kenny Werner, que estudou na Berklee entre 1970 e 1972, fala do nível do saxofonista e da influência sobre outros músicos.

Eu acho que ele estava praticamente pronto antes de chegar lá. Eu não sei quantas aulas ele tomou ou foi, mas ele principalmente teve influência sobre outros estudantes e apresentou-se muito em Boston. (...) Incrivelmente forte com seu próprio estilo e senso de direção. Incrivelmente generoso em mostrar, a mim e a outros, grandes coisas sobre música e mostrar-nos muita música que não ouviamos. Ele foi uma inspiração para todos que o conheceram. ${ }^{12}$ (WERNER, 2009).

Quando chegou aos Estados Unidos e foi informado da presença de outro brasileiro, chegado havia dois dias, Nelson Ayres tratou de ir conhecê-lo. Victor morava em um quarto alugado no porão do número 404 da Marlborough Street, o qual dividia com o pianista chileno Matias Pizarro. Coincidentemente, seu vizinho de quarto, um estudante de arquitetura, estava à procura de alguém para dividir os custos do aluguel. Desta maneira, na maior parte do tempo em que esteve em Boston, Ayres se tornou vizinho de Victor. Com a chegada de Claudio Roditi, e posteriormente do contrabaixista Zeca Assumpção, os brasileiros decidiram formar um quinteto instrumental, que contou ainda com a participação de um baterista americano chamado Buss Blackledge. 0 grupo, denominado Os Cinco, tinha uma rotina obsessiva diária de ensaios e começou a fazer apresentações nas redondezas de Boston.
Em certa ocasião houve uma apresentação dos professores de Berklee em um centro comunitário e o quinteto foi convidado para fazer a abertura. Segundo Ayres houve um grande constrangimento, uma vez que o grupo brasileiro apresentava um grande entrosamento adquirido através da maratona de ensaios. Além disso o grupo contava com Victor e Claudio, que, além de suas evidentes qualidades individuais como solistas e improvisadores, tinham um entrosamento fantástico, uma afinidade musical indescritivel.(AYRES,2009) Para completar, o grupo tocava composições originais e fazia uso de solos em instrumentos não convencionais, como berimbau. Em contrapartida, o grupo formado pelos professores apresentou standards no tradicional esquema tema-solos-tema. 0 resultado não poderia ser outro. 0 grupo dos alunos chamou mais a atenção do que o dos mestres.

A partir daquele momento, Victor passou a ter grande prestígio e consideração entre a comunidade musical de Berklee e adjacências, embora o ocorrido pudesse também ter rendido algumas manifestações de ciúmes por parte de alguns saxofonistas. 0 grupo continuou reunido até o regresso de Ayres ao Brasil em 72, chegando a tocar com a cantora Astrud Gilberto.

Se Victor Assis Brasil não era muito assíduo aos cursos disponíveis em Berklee, a rotina da escola e sobretudo o calendário escolar devem ter sido respeitados, ou levados em consideração, pelo menos por um tempo. 0 músico aproveitou o período de férias escolares para gravar no Brasil os próximos dois discos de sua carreira. Ao chegar, sugeriu ao amigo e produtor Roberto Quartin a gravação de um LP. Roberto, fã confesso do saxofonista desde os tempos do Beco das Garrafas e do Clube de Jazz e Bossa, respondeu: "Um não, dois!", ${ }^{13}$ sugerindo que gravassem um com composições de Victor e outro com composições de Antônio Carlos Jobim. Assim, entre $1^{\circ}$ e 23 de agosto de 1970 foram gravados Jobim e Esperanto. Ambos os discos foram relançados em CD no final dos anos 1990, tendo o segundo recebido o título de The Legacy. Em ambos os discos Victor é acompanhado pela guitarra de Hélio Delmiro, pelo órgão e piano de Don Salvador, o baixo de Edison Lôbo e a bateria de Edison Machado.

0 trabalho dedicado a Jobim traz em sua abertura uma versão bem livre de Wave, com longos solos construídos sobre a escala nordestina ${ }^{14}$, prenunciando um sabor regional que estaria presente em algumas composições futuras de Victor, como Arroio e Pro Zeca, mas assimilando alguma influência de free jazz. É a faixa mais extensa do disco, com 14m24s. Só tinha de ser com você e Bonita apresentam interpretações bastante convencionais, baseadas no estilo samba jazz, que foi marcante na formação de todos os músicos participantes da gravação. Dindi chama a atenção pela rearmonização cromática, e pela desconstrução da sustentação rítmica, resultando numa interpretação bastante pessoal. Este disco registra ainda a primeira gravação de Victor Assis Brasil tocando saxofone soprano. ${ }^{15}$ 
Esperanto é um disco jazzístico em sua essência. Embora a proposta fosse a gravação apenas de composições de Victor Assis Brasil, sua faixa de abertura, Gingerbread boy, na realidade foi escrita por Jimmy Heath, embora fosse incorretamente creditada a Victor ${ }^{16}$. 0 disco traz ainda a bela Marília, uma valsa cheia de lirismo, que 0 compositor viria mais tarde orquestrar para big band. Quarenta graus à sombra traz influências free, com solos simultâneos, seguindo as trilhas traçadas por John Coltrane, Ornette Coleman e outros. A faixa que encerra o disco destoa da atmosfera jazzística que o caracteriza. Ao amigo Quartin tem uma estrutura minimalista, um caráter quase litúrgico. Pode ter sido essa diversidade estilistica que levou a gravadora Atração, responsável pelo relançamento dos dois discos, a retirá-la do disco autoral, preferindo incluí-la naquele com obras de Jobim, renomeada Quartiniana $n^{\circ} 1$. Em seu lugar entraram uma versão alternativa de Marília e Friends, uma gravação que ficara excluída da edição original e que conta com a participação de Claudio Roditi.

É difícil afirmar de maneira precisa o que Victor Assis Brasil estudou em Berklee. Roberto Sion afirma que estudou composição e arranjo, além de saxofone com Joseph Viola. Zeca Assumpção afirma que ele estudou composição e arranjo, embora saliente o aspecto intuitivo de sua criação musical (ASSUMPÇÃO, 2008). De fato, ao observar seus arranjos para big band, percebe-se o desenvolvimento de uma linguagem própria, em detrimento de uma sistematização e da adoção de práticas consagradas na escola americana. Se por um lado isto resulta em trabaIhos onde se pode perceber a falta de um maior domínio de tradicionais procedimentos e técnicas de arranjo, por outro lado sobressaem a originalidade e individualidade de seu estilo, adquiridas de suas experimentações.

Em 1972, quando chegaram a Boston Célia Vaz e Roberto Sion, Victor já não frequentava mais as aulas, embora gozasse de prestígio e tivesse acesso às dependências da escola. 0 compositor tinha uma big band que lá ensaiava aos sábados, formada por brasileiros e americanos. É provável que esse prestígio se estendesse para além dos domínios de Berklee. Conforme informações constantes do programa da estreia brasileira de sua Suite para saxofone soprano e cordas, esta obra teve sua primeira apresentação em 1973 pela orquestra dos alunos do Conservatório de Boston, instituição localizada nas cercanias da Berklee.

Desta forma, o grande estímulo que Victor Assis Brasil recebeu para fomentar a sua produção foi a abundância de músicos e grupos musicais que tinha à sua disposição. 0 depoimento de Célia Vaz dá a dimensão das facilidades a que tinha acesso:

Eu acho importante essa facilidade de oportunidades da convivência com pessoas muito capazes. Isto incentiva muito o cara a escrever. Se eu tivesse uma orquestra de cordas aqui dentro do meu armário eu ia escrever uma sinfonia de seis em seis meses. [...] Provavelmente ele teve como exercitar isto muito lá.[...] Porque lá tinha as big bands à disposição, entendeu? Tinha super-músicos à disposição pra tocar o que você escrevesse. Então ele tinha gran- des pianistas pra tocar o concerto dele. Teve um concerto que 0 Kenny Werner tocou, e como o Kenny vários outros músicos maravilhosos que estavam à disposição e ansiosos pra tocar as coisas que ele escrevia. Isto é claro que é um incentivo muito grande pra qualquer compositor, você ter quem toque maravilhosamente sua obra, quem que não quer? Aqui você escreve e guarda numa gaveta porque não tem onde tocar. É muito mais difícil você conseguir alguém pra tocar um concerto seu pra piano e cordas, ou piano e sinfônica, do que lá. Ainda mais em Boston, onde havia milhares de escolas, milhares de músicos de todos os niveis e de todos os lugares do mundo, você tem na esquina. Sempre tinha alguém bom pra tocar aquilo. (VAZ, 2008)

Assim, mais que a formação que o compositor pudesse vir a ter nas classes de Berklee, foi o imenso, farto laboratório musical que teve à disposição que incentivou a sua criação, abrindo caminho para a expansão de sua música para além da linguagem puramente jazzística.

\section{3 - 0 retorno de Victor Assis ao Brasil}

Em 1974 Victor Assis Brasil decidiu voltar ao Brasil. Desta vez seu grande amigo e parceiro Claudio Roditi não seguiu seus passos, permanecendo nos Estados Unidos, onde até hoje tem uma bem sucedida carreira musical, sendo um dos mais reconhecidos e respeitados trompetistas da atualidade. Victor seguiu seu caminho comandando pequenos grupos, tendo gravado mais três discos: Victor Assis Brasil, gravado ao vivo em 1974 no Teatro da Galeria; Victor Assis Brasil Quinteto, de 1979 e Pedrinho, de 1980. Uma apresentação em duo com o pianista Luiz Eça, no Museu de Arte Moderna do Rio de Janeiro, em 1977, seria postumamente lançada em CD. Participaria ainda do Festival de Jazz de São Paulo, em 1978.

Victor escreveu também música para cinema ${ }^{17}$ e televisão. Trabalhou como arranjador na Rede Globo de Televisão, tendo composto a música para a novela 0 Grito, exibida entre 1975 e 1976, cuja trilha sonora encontra-se disponível no mercado em CD. Normalmente este tipo de coletânea é usado como estratégia de mercado para inserir ou consolidar cantores no circuito da música comercial. Todavia, além das canções populares usualmente incluidas neste produto televisivo-fonográfico, o disco traz também quatro composições de Victor. Pode-se deduzir de sua escuta que apesar dos problemas que possa ter tido em conciliar seus princípios de criação musical com os interesses comerciais da emissora, do que Radamés Gnattali também se queixava (BARBOSA e DEVOS, 1985), no curto período em que lá trabalhou o saxofonista pôde por em prática suas habilidades de arranjador e compositor. A Globo dispunha na época de uma orquestra no modelo conhecido como jazz-sinfônica, reunindo cordas, metais, madeiras (aí incluídos os saxofones) e seção rítmica. 0 compositor utilizou o grupo para fazer o registro das suas composições que integram o disco.

Tema em 5/4 tem uma forma binária $A B A$ e um caráter regionalista evidenciado em sua exposição modal. Na segunda seção destaca-se um coral de trombones. Em 0 Grito o compositor aproveita o tema de uma das seções de uma outra composição, Dialogues. 
Berceuse é apresentada pelo trio Radamés Gnattali, provavelmente formado pelo próprio Radamés, ao piano, e integrantes da orquestra global. Tem a candura compatível com seu título e uma inspiração romântica. Vice-Versa, executada por uma big band, com destaque para as flautas, sintetiza a mistura estilística de Victor Brasil, onde jazz, música brasileira urbana e regional e música clássica convergem.

A música entrou na vida de Victor por muitas vias. A primeira delas foi a herança familiar, através da influência da avó maestrina e, sobretudo, do irmão João Carlos, por quem nutria um profundo sentimento de admiração. Houve também uma sensibilidade incomum, um grande senso intuitivo e um talento para desvendar seus próprios caminhos. 0 ambiente musical de meados dos anos 1960, o impacto da bossa-nova e do jazz serviu para nortear o seu trabalho, definindo a corrente principal.

0 periodo que passou em Boston forneceu as condições para assimilar e fundir as diversas fontes que acabaram por definir o seu estilo. Pôde o compositor lá, através de um trabalho de experimentação, tentativa e erro, burilar suas habilidades como compositor e arranjador. Seu depoimento em matéria da revista Veja, em 1974, confirma isto. "De 1970 a 1974 tive a oportunidade de ouvir e tocar tranquilamente. Eu organizava grupos e orquestras e aprendia ouvindo meus erros. Invadi então outras esferas" (in SOUZA, 1974, p 83).

0 programa do concerto da estreia brasileira de sua Suíte para saxofone soprano e cordas, traz um depoimento do compositor que dá a noção do caldeirão onde se fundiram as diversas vertentes que formaram seu estilo musical. Victor define a obra como "uma sintese de suas experiências musicais, abrangendo Pergolesi, Villa-Lobos, Stravinsky e Ravel, amalgamados com a vivência jazzística fundamental em sua formação".

Embora o lado jazzístico tenha se tornado o mais conhecido de sua carreira, o que pode ser comprovado pelos discos que gravou, é importante lembrar que o compositor não queria que sua música ficasse confinada aos limites do jazz. Em 1977 o compositor declararia:

\footnotetext{
"Esse rótulo de jazz não tem nada mais a ver comigo. Estudo música há algum tempo, escrevi um concerto para piano e orquestra, uma suite para quarteto de cordas e gostaria que o público soubesse dessa minha faceta." (in MILARCH, 1977, p.1).
}

Victor deixou um legado de cerca de 400 composições inéditas. A morte prematura, aos 35 anos de idade, o impediu de conseguir divulgar a pluralidade de seu trabalho.

0 pianista João Carlos Assis Brasil contou recentemente que ele e seu irmão chegaram a pensar em realizar um trabalho conjunto, tocando música clássica, mas que não houve tempo para tal (BRASIL, 2008). É interessante notar como os irmãos gêmeos acabaram chegando a um ponto muito próximo. Victor, tão estigmatizado pelo rótulo de jazzista, assimilou em sua música várias outras vertentes. João Carlos, por sua vez, com sua carreira de pianista clássico, acabou por fazer várias incursões no campo da música popular e do jazz. Em seu disco Self Portrait, de 1990, prestou um tributo ao irmão saxofonista, apresentado várias de obras inéditas, onde fica claro como podem ser tênues as linhas que separam os diversos gêneros e estilos musicais.

\section{5 - Conclusão}

A vida de Victor Assis Brasil foi marcada por suas escolhas. 0 músico decidiu enfrentar um difícil caminho, renunciando aos apelos do circuito musical comercial e abraçando a causa de sobreviver no Brasil da música na qual acreditava. Mesmo pagando um alto custo, manteve-se fiel aos seus princípios. Poderia ter permanecido na Europa, ou mesmo nos Estados Unidos, como fez o amigo Claudio Roditi. Lá talvez tivesse melhores condições para desenvolver o seu trabalho. Contudo, preferiu ficar no Brasil e encarar sua cruzada. Tornou-se assim um músico emblemático.

Seu nome é sempre lembrado quando se refere à prática do jazz em terras brasileiras e sua música ajudou a fornecer as bases da linguagem da moderna música brasileira instrumental. Seus objetivos primários de fato foram se estabelecer como músico de jazz, mas sua música logo extrapolou esses limites. Partindo da linguagem jazzística em que era fluente, tratou de assimilar os elementos musicais que estiveram presentes na sua formação: a bossa-nova, os ritmos brasileiros, a música clássica que conhecera através do irmão. Os quatro anos em que viveu em Boston tiveram uma importância crucial nesse processo. Através da abundância de recursos humanos, do ambiente musical e das condições físicas que lhe permitiram a criação de diversos grupos e orquestras, o músico pode expandir seus horizontes. A maior parte de sua produção é dessa época. Através da experimentação o compositor amalgamou as diversas referências musicais e consolidou seu estilo composicional. Infelizmente, após o seu regresso ao Brasil, teve poucas oportunidades de pôr em prática a vivência adquirida em Berklee e de apresentar suas composições. Passados todos esses anos, a maioria delas permanece inédita. Espera-se que, através de esforços como o desta pesquisa, esta parcela de seu legado se torne mais conhecida. Uma música que não tem fronteiras, que não se envergonha em usar a linguagem jazzística como um meio natural de expressão, mas que também incorpora elementos brasileiros e mesmo da música clássica. A mistura de John Coltrane, Luiz Gonzaga e Debussy, afinal, "dá samba".

Esta pesquisa se concentra na linha da teoria e prática da interpretação, tendo, portanto entre seus objetivos o levantamento de repertório e a discussão de soluções interpretativas. Na impossibilidade de se ter acesso à Suíte para saxofone soprano e cordas, seja na forma de sua partitura, seja na forma de gravação que possa ser objeto de transcrição, o foco será direcionado a outras obras que reúnam as mesmas características de fusão de elementos de jazz, música popular brasileira e música clássica, preferencialmen- 
te as que façam uso do saxofone em sua instrumentação. Obviamente não seria possivel analisar detalhadamente cada uma das 37 obras listadas na tabela 1. Portanto, será feito um recorte sobre três ou quatro composições, fornecendo assim um panorama de sua produção. Desta forma configuram-se objetos de estudo em potencial as obras para big band, Saxophone Quartet \# 1, o Prelude for alto saxophone and Piano, Reflexos, Osmosis, Suite for a Lost Lady, por representarem as várias formações instrumentais e tendências composicionais deste repertório. Sobre as obras selecionadas serão aplicadas ferramentas analíticas que permitam identificar os elementos característicos de cada estilo presente em sua criação. A definição do modelo mais adequado para a análise constitui-se assim um dos próximos passos da pesquisa.

Espera-se fornecer subsídios para uma compreensão mais ampla deste repertório, permitindo ao intérprete fazer suas escolhas baseado no equilibrio dos elementos de música clássica e popular. Acredita-se ainda que esta discussão possa contribuir para a diminuição da barreira que costuma separar saxofonistas de formação clássica dos de formação jazzística, mostrando que existem muito mais pontos em comum que divergência entre as duas linhas de trabalho, e que a Música, em suma, está acima desta questão de fronteiras de estilos e gêneros.

\section{Referências}

ALVES, Izilda. A despedida de Victor Assis Brasil. Folha de São Paulo, São Paulo, 6 jun. 1977. Folha Ilustrada, p.21.

BLAKE, Ran. Third Stream and the Importance of the Ear. A position paper in Narrative Form. In: College Music Symposium, Volume 21/2, Fall, 1981. Disponivel em <http://www.music.org/cgi-bin/symp_show.pl?h=36\&tf=28ctid=277>. Acesso em: 28 de mar. de 2009.

BARBOSA, Valdinha \& DEVOS, Anne Marie. Radamés Gnattali, o eterno experimentador. Rio de Janeiro: FUNARTE/ Instituto Nacional de Música, 1985.

BARRETO, Leonardo. Pro Zeca de Victor Assis Brasil: aspectos do hibridismo na música instrumental brasileira. 2007. Dissertação (Mestrado em música). UFMG - Universidade Federal de Minas Gerais.

BERKLEE COLLEGE OF MUSIC HOME PAGE. Disponivel em <http://www.berklee.edu>. Acesso em 20 fev. 2009.

BEZERRA, V. A. - Victor Assis Brasil (1945-1981). In E- jazz, o site do jazz e da música instrumental brasileira. Disponível em < http://www.e jazz.com.br/detalhes-artistas.asp?cd=164>. Acesso em: 23 fev. 2009.

BORELLI, Marcos. Victor Assis Brasil. Disponível em <http://assisbrasil.org/vitorbio.html>. Acesso em: 23 fev. 2009.

BRASIL, Victor Assis. Partituras, vol. 1. Seleção Paulo Assis Brasil. Rio de Janeiro: Compasso Produções Artísticas, 2001.

CASTRO, Rui. Chega de Saudade: A história e as histórias da Bossa Nova. São Paulo: Companhia das Letras, 2008.

CLAM - Centro Livre de Aprendizagem musical. Nossa História. Disponivel em <http://www.clamzimbo.com.br/principal. html>. Acesso em 17 fev. 2009.

DANIELS, Eddie. Biography. In: Eddie Daniels Home Page. Disponível em <http://www.eddiedanielsclarinet.com/bio.html>. Acesso em 15 fev. 2009.

DAUELSBERG, Claudio Peter. A importância da improvisação na formação musical do intérprete. 2001. Dissertação (Mestrado em Música) - Universidade Federal do Rio de Janeiro.

ALBIN, Ricardo Cravo. Dicionário Cravo Albin da Música Brasileira. Disponível em <http://www.dicionariompb.com.br>. Acesso em 10 out. 2006.

DIEKEN Sandra - Curriculum vitae. Disponivel em <http://www.myballet.de/index.php?id=636CtL=0>. Acesso em $14 / 02 / 2009$.

DYER, Richards. Composer Builds a Bridg between Classical And jazz. The Boston Globe. Boston, 19 out. 2003. Seção Arts/ Entertainment. P. N6.

E-PIPOCA. Sala Vip.A Rainha da Noite. Disponivel em <http://epipoca.uol.com.br/filmes_detalhes.php?idf=11873>. Disponivel em 23 fev. 2009.

FIGUEIREDO, Afonso C. S. Improvisação no Saxofone: A Prática da Improvisação Melódica na Música Instrumental do Rio de Janeiro a partir de meados do século XX. 2005. Tese (Doutorado em Música) - Programa de Pós-Graduação em Música, Universidade Federal do Estado do Rio de Janeiro.

GIOIA, Ted. The History of Jazz. New York: Oxford University Press, 1997. 
G. SCHIRMER INC. Associated music publishers, inc. - Gunther Schuller. Informação disponivel em <http://www.schirmer. com/default.aspx?Tabld=2419๕tState_2872=2氏tComposerld_2872=1400>. Acesso em 13 fev. 2009.

GUEST, lan. Curriculum Vitae. Disponivel em <http://www.mariana.com.br/ianguest/cvitae.htm>. Acesso em 17 fev. 2009.

MAURITY, Fernando Trocado. Improvisação em Victor Assis Brasil. 2006. Dissertação (Mestrado em Música) - Universidade Federal do Rio de Janeiro.

MILLARCH, Aramis. A Batalha de Assis. Estado do Paraná. Curitiba, 27 de abril de 1975. Jornal da Música Popular, p.44. . Jazz não jaz. Vive, hoje, no Guairá. Estado do Paraná. Curitiba, 03 de junho de 1977. Almanaque. Tablóide, p.1.

NEW ENGLAND CONSERVATORY. Gunther Schuller. Disponivel em <http://necmusic.edu/study-nec/libraries/archivesspecial-collections/archival-holdings/director/president/gunther-schull >. Acesso em 24 out. 2009.

ORQUESTRA SINFÔNICA NACIONAL. Notas de programa do concerto inaugural da temporada 1976. 2 mai. 1976. Rio de Janeiro. Sala Cecilia Meireles.

RAFAELLI, José Domingos. Victor Assis Brasil. Disponivel em <http://assisbrasil.org/vitorbio.html>. Acesso em 23 fev. 2009.

SARAIVA, Joana Martins. A invenção do sambajazz: discursos sobre a cena musical de Copacabana no final dos anos de 1950 e início dos anos 1960. 2007. Dissertação (Mestrado em História). Pontifícia Universidade Católica do Rio de Janeiro.

SCHULLER, Gunther. Early Jazz: Its Roots and Musical Development (History of Jazz). New York: Oxford University Press,USA, 1986. Musings: the Musical Worlds of Gunther Schuller. New York: Oxford University Press, USA, 1989.

The Swing Era: The Development of Jazz, 1930-1945 (The History of Jazz), New York: Oxford University Press, USA, 1989.

. Encounters - Program notes. In G. SCHIRMER INC. Associated music publishers, inc. Disponivel em <http://www. schirmer.com/default.aspx?Tabld=2420\&State_2874=2氏tworkld_2874=32660>. Acesso em 13 fev. 2009.

SEGELL, Michael. The Devil's Horn: The Story of the Saxophone, from Noisy Novelty to King of Cool. New York: Picador, 2006.

SOUZA, Tárik de. Um sax a mais. Revista Veja, São Paulo, n³24, p.83, 1974.

THE INTERNET MOVIE DATABASE. The Cast and Crew for MARÍLIA e MARINA. Disponivel em <http://www.imdb.com/ title/tt0188881/fullcredits\#writers>. Acesso em 23 fev. 2009.

\section{Entrevistas e e-mails recebidos}

AYRES, Nelson. Entrevista realizada em São Paulo, 19/01/2009. Arquivo digital (24m29s).

ASSUMPÇÃO, Zeca. Entrevista realizada no Rio de Janeiro, 14/10/2008. Arquivo digital (27m13s).

BRASIL, João Carlos Assis. Entrevista realizada no Rio de Janeiro, 27/10/2008. Arquivo digital (23m48s).

GOMES, Alfredo. Entrevista realizada no Rio de Janeiro, 07/10/2008. Arquivo digital (45m39s).

RODITI, Claudio. Mensagens recebidas por mtuliosax@gmail.com em 08/10/2008 e 10/01/2009.

SION, Roberto. Entrevista realizada em São Paulo, 19/01/2009. Arquivo digital (1h13m1s).

VAZ, Célia. Entrevista realizada no Rio de Janeiro, 22/10/2009. Arquivo digital (32m17s).

WERNER, Kenny. Mensagem recebida por mtuliosax@gmail.com em 05/01/2009.

\section{Discos}

BRASIL, Victor Assis. Desenhos. Rio de Janeiro: Forma. 1966. 1 LP (45m42s). FM 17.

Trajeto. Rio de Janeiro: Equipe. 1968. 1 LP (38m45s).

Victor Assis Brasil. Rio de Janeiro: Magic Music (CID). 1974. 1 LP (43m.49s). MM 3010.

Victor Assis Brasil Quinteto. Rio de Janeiro: EMI-Odeon. 1979. 1 LP (43m18s). 064422844.

. Pedrinho. Rio de Janeiro: EMI-Odeon, 1980. 1 LP (37m08s). 064422856.

Jobim. Rio de Janeiro: Atração Fonográfica, 2003. 1 CD (37m13s).ATR 32006.

The Legacy. Rio de Janeiro: Atração Fonográfica, 1999. 1 CD (43m57s). ATR 31058.

EÇA, Luiz; BRASIL, Victor Assis. Ao Vivo no Museu de Arte Moderna. Rio de Janeiro: Imagem, 1997. 1 CD (75m02s).

0 GRITO. Rio de Janeiro: Som Livre, 2001. 1 CD (31 m10s). 3021-2. 


\section{Notas}

10 conceito de música clássica é aqui empregado em seu sentido amplo, abrangendo a música de concerto. Para uma discussão sobre essa terminologia consultar PINTO, Marco Túlio de Paula. O Saxofone na música de Radamés Gnattali. Dissertação de mestrado. Rio de Janeiro, UNIRIO - Universidade Federal do Estado do Rio de Janeiro, 2005.

2 "...the modern age is marked by the tendency for distinct styles to coalesce and cross-fertilize. In music, purity is a myth, albeit a resilient one. The historian who hopes to come to grips with the powerful currents of creativity in modern times must learn to deal with these composite art forms on their own terms or not at all. There is no high road on the postmodern map, just a myriad of intersecting and diverging paths."

3 Encounters is an improbable and deliriously appealing masterpiece scored for 150 players, including expanded orchestra, keyboards, jazz ensemble, and jazz soloists. The piece starts with a barbaric yawp, then a sighing motive; both figure throughout. The classical and jazz groups alternate but soon begin to interact on shared musical material. Loose-limbed jazz often tends to steal the show from strait-laced classical groups, but Schuller's ear and imagination for orchestral color doesn't let that happen; the third movement, with its rumblings of unusual low bass instruments, is magical Bartokian night music. The climax lifts you out of your seat.

4 Recentemente descobriu-se uma versão desta obra para flauta e piano, em posse do compositor Nelson Ayres, em São Paulo.

5 Há controvérsias sobre quando Victor ganhou o instrumento. Os textos de Borelli e Rafaelli disponiveis em <http://assisbrasil.org/vitorbio.html> afirmam que ele teria recebido o saxofone quando tinha 17 anos. Já o depoimento de João Carlos Assis aponta para o fato ter acontecido quando Victor tinha 13 ou 14 anos.

6 Informação disponivel em http://assisbrasil.org/vitorbio.html.

70 compositor deu títulos em inglês para diversas composições. Waltz for Phil, Waltz for Trane e Waltzing são exemplos de composições baseadas no ritmo da dança em compasso $3 / 4$.

8 No jargão da música popular, figuração rítmica ostensiva que caracteriza um determinado estilo musical.

9 Alfredo Gomes afirma em entrevista que também foram gravadas faixas com a participação do sexteto, mas que, por decisão da gravadora, estas não foram incluídas LP.

10 Denominação adotada a partir de 1970. Denominava-se Schillinger House desde sua fundação, em 1945, até 1960, quando passou a se denominar Berklee School of Music.

11 Dados disponiveis no sítio da instituição: <http://www.berklee.edu/about/facts.html>

12 I think he was pretty finished before he got there. I don't know how many classes he took or went to, but he mostly had influence on other students and performed quite a lot in Boston. (...) Incredibly strong with his own style and sense of direction. Incredibly generous in showing me and others great things about music and turning us on to much music we didn't hear. He was an inspiration to all who knew him

13 Conforme declaração no encarte do relançamento em CD de Victor Assis Brasil - Jobim.

14 Escala maior com a quarta aumentada e a sétima abaixada. No jazz essa escala é também conhecida como lídio dominante, lídio mixolídio ou lídio bemol 7.

15 Victor também usa este instrumento em vários momentos de Esperanto. Porém, ao contrário de Jobim, este disco esperou alguns anos para ser lançado.

16 Esta informação errônea foi corrigida no relançamento do disco, em 1999.

17 Sua biografia disponivel em< http://victorassisbrasil.com.br/frame01.htm> afirma ter ele composto a trilha do filme Marilia e Marina. Entretanto, o sitio The Internet Movie Database (disponivel em http://www.imdb.com) credita a trilha deste filme, dirigido por Luiz Fernando Goulart em 1976, a Francis Hime e Vinícius de Moraes. Esta informação é confirmada pelo sítio e-pipoca ( Entretanto, o mesmo sítio dá o crédito a Victor da trilha do filme A Rainha do Rádio, do mesmo diretor, em 1979).

Marco Túlio de Paula Pinto é Professor de Saxofone da UNIRIO. Professor de saxofone no PIM (Programa de Integração pela Música) do município de Vassouras (RJ) entre 2007 e 2008. Bacharel em Saxofone pela UFRJ e Mestre em práticas interpretativas pela UNIRIO, instituição na qual cursa atualmente o Doutorado em Teoria e Prática da Interpretação. Integrou a UFRJazz Ensemble entre 1998 e 2007. Apresentou-se como solista junto a grupos como OSPA, ORSEM, Orquestra Sinfônica de Barra Mansa, Banda Sinfônica da CSN e Banda Sinfônica da FEBAM. Ao lado do pianista Alexandre Freitas, desenvolve trabalho de divulgação da música brasileira para saxofone e piano. No campo popular trabalhou com diversos artistas, como Luiz Melodia, Jorge Vercilo, Flavio Venturini, Chico César, Gilson Peranzzetta e Nivaldo Ornelas, entre outros. 